\title{
Implantologie
}

\section{Variobase Sekundärteil-Sortiment erweitert}

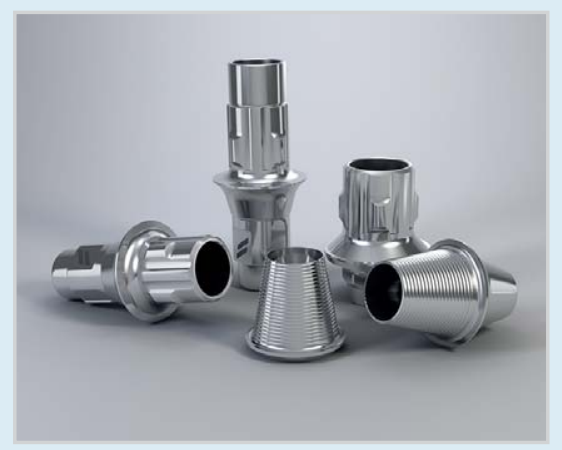

Mit zusätzlichen Variobase Sekundärteilen vergrößert Straumann die Gestaltungsmöglichkeiten von Restaurationen. Bei höheren Kronen bietet das Unternehmen jetzt das Variobase Sekundärteil mit 5,5 mm Schafthöhe. Der Schaft kann bis auf 3,5 mm gekürzt werden. Bei mehrgliedrigen Restaurationen ermöglicht das neue Produkt für Brücke/Steg flexible, effiziente Lösungen. Die konische Form mit Spiralgewinde sowie die Dimensionen des Referenzrands schaffen optimale Voraussetzungen für Langzeitstabilität von Brücken- oder Stegversorgungen. Die Variobase für CEREC bietet die zuverlässige Original-Verbindung zwischen Implantat und Restauration für Sirona-Anwender. Sie ist mit den am Markt erhältlichen Materialblocks sowie Scankörpern kompatibel. Mehr Informationen unter http:// www.straumann.de/variobaseinfos

Nach einer Pressemitteilung der Straumann GmbH, Freiburg 